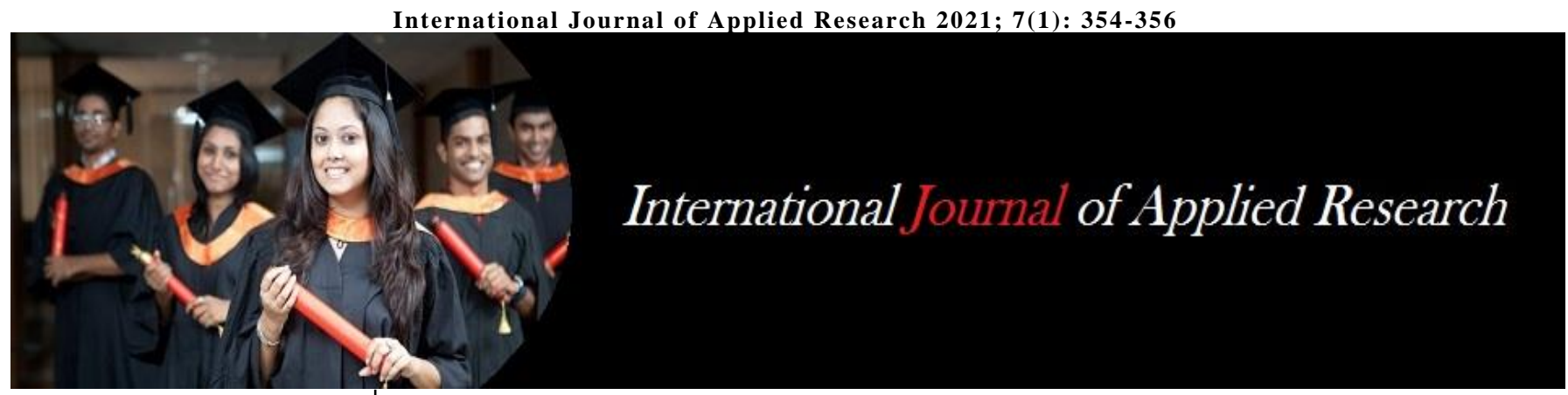

ISSN Print: 2394-7500 ISSN Online: 2394-5869 Impact Factor: 8.4 IJAR 2021; 7(1): 354-356 www.allresearchjournal.com Received: 27-11-2020 Accepted: 30-12-2020

Priyadarshini Waikhom M.Sc. Nursing (MSN), Symbiosis College of Nursing Constituent of Symbiosis International University, Pune, Maharashtra, India

\title{
Assessing the level of depression and coping strategy adopted by cancer patients
}

\section{Priyadarshini Waikhom}

DOI: https://doi.org/10.22271/allresearch.2021.v7.i1e.8207

\section{Abstract}

Introduction: World Health Organization defines health as an state of complete physical mental and social well being and not merely an absence of disease or infirmity. A healthy person is an asset to the society. An unhealthy lifestyle and practices among an individual will lead to a disease.

Material and Method: A Quantitative research approach and descriptive research design was used. Cancer patients admitted in Yashwantrao Chavan Memorial Hospital, Pune, were used to collect the data. A total sample of 40 cancer patient was selected by convenience non probability sampling technique. Data was collected using modified Beck Depression Inventory assessing the level of depression and cope scale to assess the coping strategy.

Results: $42.5 \%$ of the cancer patients had moderate depression (score 21-30), 20\% of them had borderline clinical disturbance (17-20), 17.5\% of them had mild depression (score 11-16), 17.5\% of them had normal depression (score 1-10) and 2.5\% of them had severe depression (Score 31-40). Majority of $97.5 \%$ of the cancer patients had average coping (score 73-114) and $2.5 \%$ of them had good coping strategy (Score 115-155).

Conclusion: The correlation between depression and coping found negative is statistically significant. More the depressed is the cancer patients, poor is his coping. There was no significant association between depression of cancer patients and their demographic variables.

\section{Keywords: depression, coping strategy, cancer patients}

\section{Introduction}

Cancer is both a physical disease and a condition that has predominant psychosocial effects, contains uncertainties and threatens life leading to severe psychological problems in an individual. Patients with cancer face most of the stressors associated with diagnosis, illness and treatment. These stressors may generate coping strategy, which may affect the mental health. Cancer affects patients' lives and those of their families in different aspects. Cancer diagnosis and treatment brings changes in patients' personal paths of life, in their daily activities, work, relationships, and family roles, and it is associated with a high level of patient psychological stress. This stress shows up as anxiety and/or depression ${ }^{[1]}$.

Anxiety and depression is the most common psychological problem encountered in patients with cancer. Anxiety can be defined as an unpleasant subjective experience associated with the perception of real or imagined threat and is a common symptom in connection with cancer $^{[2]}$.

Human beings are motivated to find meaning in their lives. At no time is this more evident than in the aftermath of a traumatic event. Events that pose physical harm or death can shatter one's schemas of a just, purposeful world and an invulnerable self. A cancer diagnosis is one such event. The diagnosis brings acute emotional distress, and individuals struggle with questions about why the disease struck them, its significance for their future, and the changes that may follow ${ }^{[3]}$.

Different individuals use different strategies for coping with negative affective state and associated life problems. Strategies are developed to identify means to reduce stress. Such coping mechanisms are important both in periods of acute stress/emergencies (such as hurricane disasters) as well as in patients suffering from chronic illnesses such as depression, breast cancer, and HIV/AIDS ${ }^{[4]}$.
Priyadarshini Waikhom M.Sc. Nursing (MSN), Symbiosis College of Nursing Constituent of Symbiosis International University, Pune, Maharashtra, India 
The use of some of these coping styles may prove beneficial for the person. For example, in a study on the coping mechanisms and depression in elderly medically ill men, a high proportion of the respondents sought comfort in religious beliefs and practices. This in turn was inversely related to their severity of depression ${ }^{[5]}$.

Coping has been identified as a critical factor in the mediation of effects of stressful life events on the individual's physical and psychological adaptation. Lazarus \& Folkman have defined coping as 'constantly changing cognitive and behavioral efforts to manage specific external and/or internal demands that are appraised as taxing or exceeding the resources of the person'. The concept has been extended from research on stressful events to psychosocial adaptation to chronic disease. Coping is seen to have three main functions: elimination or modification of the problem causing the distress, alteration of the meaning of the experience, and regulation of emotional distress. These functions are often termed problem-focused coping, appraisal-focused coping and emotion-focused coping ${ }^{[6]}$.

\section{Methodology}

The objectives of the study were to assess the level of depression adopted by cancer patients and to assess the coping strategy adopted by cancer patients.
A descriptive survey approach was adopted using descriptive survey design. The study was conducted from April 2013 to April 2014, among cancer patients associated hospital at Pune. The study population comprised of patients suffering from cancer. The sample size was 40 cancer patients. Purposive sampling technique was adopted to select the samples. Modified Beck Depression Inventory and Modified Cope Scale was used to assess the level of depression and coping strategy adopted by cancer patients. The depression score was classified as normal, mild, borderline clinical depression, moderate and severe. And cope scale was classified as good, average and poor.

The questionnaire was administered to all the cancer patients for the study and who were willing to participate in the study.

\section{Results}

$42.5 \%$ of the cancer patients had moderate depression (score $21-30), 20 \%$ of them had borderline clinical disturbance $(17-20), 17.5 \%$ of them had mild depression (score 11-16), $17.5 \%$ of them had normal depression (score 1-10) and $2.5 \%$ of them had severe depression (Score 31-40).

Majority of $97.5 \%$ of the cancer patients had average coping (score 73-114) and $2.5 \%$ of them had good coping strategy (Score 115-155)

Table 1: Level of depression adopted by cancer patients

\begin{tabular}{|c|c|c|}
\hline Depression & Frequency & \% \\
\hline Normal (Score 1-10) & 7 & $17.5 \%$ \\
\hline Mild (Score 11-16) & 7 & $17.5 \%$ \\
\hline Borderline clinical disturbance (Score 17-20) & 8 & $20.0 \%$ \\
\hline Moderate (Score 21-30) & 17 & $42.5 \%$ \\
\hline Severe (Score 31-40) & 1 & $2.5 \%$ \\
\hline
\end{tabular}

Table 2: Level of coping strategy adopted by cancer patients

\begin{tabular}{|c|c|c|}
\hline Coping & Frequency & \% \\
\hline Poor (Score 31-72) & 0 & $0.0 \%$ \\
\hline Average (Score 73-114) & 39 & $97.5 \%$ \\
\hline Good (Score 115-155) & 1 & $2.5 \%$ \\
\hline
\end{tabular}

The correlation between depression and coping scores was assessed using Pearson's correlation coefficient. The value of Pearson's correlation coefficient was found to be -0.383 , which is negative indicating that there is negative correlation between depression score and coping score. The significance of this correlation was tested using t-test with $(n-2=38)$ degrees of freedom. T-value for this test was found to be -2.55 with 38 degrees of freedom. Corresponding pvalue was 0.007 . This $\mathrm{p}$-value is small (less than 0.05 ), the null hypothesis is rejected. The correlation between depression and coping found negative is statistically significant. More the depressed is the cancer patients, poor is his coping.

\section{Discussion}

The present study was undertaken to assess the level of depression and coping strategy adopted by cancer patients. Depression is said to be the least noticed symptom in people with cancer but it is also the hardest to cope with. In the present study it was found that majority of the patients (42.5\%) who had cancer were moderately depressed.

A study conducted by Andrykowski, Lykins and Floyd (2008) documented a great variability of depression ranging from $0 \%$ to $58 \%$ in patients with neoplasm. With the findings in the present study supported, it can be said that cancer patients are depressed with varying levels of depression. But at the same time with the present study having less number of samples it is not conclusive of the level of depression cancer patients usually have ${ }^{[7]}$.

Results from the Roesch et $\mathrm{al}^{14}$ meta-analyses indicated that men who used an avoidant coping strategy in response to their prostate cancer diagnosis tended to have poorer physical and psychological health. In contrast, those men who adopted an active or approach-oriented coping strategy (involving either problem- or emotion-focused coping) had improved physical and psychological well-being ${ }^{[8]}$.

\section{Conclusion}

The study concluded that $42.5 \%$ of the cancer patients had moderate depression (score 21-30), 20\% of them had borderline clinical disturbance (17-20), $17.5 \%$ of them had mild depression (score 11-16), 17.5\% of them had normal depression (score 1-10) and $2.5 \%$ of them had severe depression (Score 31-40).

Majority of $97.5 \%$ of the cancer patients had average coping (score 73-114) and $2.5 \%$ of them had good coping strategy (Score 115-155).

\section{Recommendations}

Keeping in view the findings of the present study, the following recommendations were made.

- A similar study can be replicated in different setting to strengthen the findings. 
- The same study could be replicated on a large sample size.

- Same study can be replicated on diabetic

\section{Acknowledgement}

I praise and thank the Almighty God for His grace and blessings for guiding me throughout my study without which nothing could have been possible. It is a great pleasure to extend my deepest gratitude to my revered teacher and guide, Mrs. Meenakshi Gijare, Deputy Director, Symbiosis College of Nursing, Pune.

\section{References}

1. Karabulutlu EY, Bilici M, Çayır K, Tekin SB, Kantarcı R. Coping, Anxiety and Depression in Turkish Patients with Cancer. Eur J Gen Med 2010;7(3):296-02

2. Ahlberg K, Ekman T, Wallgren A, Johansson GF. Fatigue, psychological distress, coping and quality of life in patients with uterine cancer. J Adv Nurs 2004;45:205-13.

3. Jim HS, Richardson SA, Golden-Kreutz DM, Andersen BL. Strategies Used in Coping With a Cancer Diagnosis Predict Meaning in Life for Survivors. Health Psychol 2006;25(6):753-76. doi: 10.1037/0278-6133.25.6.753

4. Kasi PM, Naqvi HA, Afghan AK, Khawar T, Khan FH, Khan UZ et al. Coping Styles in Patients with Anxiety and Depression. ISRN Psychiatry 2012, 1-7. doi:10.5402/2012/128672

5. Koenig HG, Cohen HJ, Blazer DG et al. Religious coping and depression among elderly, hospitalized medically ill men. American Journal of Psychiatry, 1992;149(12):1693-1700.

6. Lampic C, Wennberg A, Schill J, Glimelius B, Brodin $\mathrm{O}$, Sjoden P. Coping, psychosocial well-being and anxiety in cancer patients at follow-up visits. Acta Oncologica 1994;33(8):887-894.

7. Andrykowski MA, Lykins E, Floyd A. Psychological Health in Cancer Survivors. Seminars in Oncology Nursing 24(3), 193-201. doi:10.1016/j.soncn.2008.05.007

8. Roesch SC, Adams L, Hines A et al. Coping with prostate cancer: a meta-analytic review. J Behav Med 2005;28(3):281-293. 